\title{
Turner syndrome and sexual differentiation of the brain: implications for understanding male-biased neurodevelopmental disorders
}

\author{
Rebecca Christine Knickmeyer • Marsha Davenport
}

Received: 18 April 2011 / Accepted: 13 July 2011 /Published online: 5 August 2011

(C) Springer Science+Business Media, LLC 2011

\begin{abstract}
Turner syndrome (TS) is one of the most common sex chromosome abnormalities. Affected individuals often show a unique pattern of cognitive strengths and weaknesses and are at increased risk for a number of other neurodevelopmental conditions, many of which are more common in typical males than typical females (e.g., autism and attention-deficit hyperactivity disorder). This phenotype may reflect gonadal steroid deficiency, haploinsufficiency of $\mathrm{X}$ chromosome genes, failure to express parentally imprinted genes, and the uncovering of $\mathrm{X}$ chromosome mutations. Understanding the contribution of these different mechanisms to outcome has the potential to improve clinical care for individuals with TS and to better our understanding of the differential vulnerability to and expression of neurodevelopmental disorders in males and females. In this paper, we review what is currently known about cognition and brain development in individuals with TS, discuss underlying mechanisms and their relevance to understanding male-biased neurodevelopmental conditions, and suggest directions for future research.
\end{abstract}

Keywords Turner syndrome $\cdot \mathrm{X}$ chromosome . Gonadal steroid · Estrogen

\section{R. C. Knickmeyer $(\bowtie)$}

Department of Psychiatry CB 7160 ,

University of North Carolina at Chapel Hill,

343 Medical Wings C, Campus Box \#7160,

Chapel Hill, NC 27599-7160, USA

e-mail: rebecca_knickmeyer@med.unc.edu

M. Davenport

Department of Pediatrics CB 7039,

University of North Carolina at Chapel Hill,

Chapel Hill, NC 27599-7039, USA
Many early onset neurodevelopmental disorders are malebiased, that is they occur significantly more often in males than females. These include autism spectrum conditions (ASC; 4:1 to 9:1) (Baird et al. 2000; Chakrabarti and Fombonne 2001), attention-deficit hyperactivity disorder (ADHD; 3:1 to 5:1) (Szatmari et al. 1989; Moffitt 1990), early onset persistent antisocial behavior (10:1) (Moffitt and Caspi 2001), reading disability (2:1) (Liederman et al. 2005), language delay (2:1) (Salameh et al. 2002; Nelson et al. 2006), and Tourette's syndrome (9:2) (Wang and Kuo 2003). Intrinsic biological factors are likely to explain much of the male-bias in these disorders, although sex differences in exposure to environmental risks and/or protective factors, societal expectations and values related to gender, referral biases, or biased assessments are likely contributors as well (Rutter et al. 2003). Specifically, X chromosome effects and early exposure to gonadal hormones (androgens and estrogens) appear to be the most important determinants of sexual differentiation of the brain.

\section{Two pathways to a sexually differentiated brain}

First, experiments in animals clearly demonstrate that gonadal hormones produced in fetal and neonatal life act on the brain to produce sex differences in neural structure and function (De Vries and Simerly 2002; Simerly 2002). Gonadal hormones affect neural development by preventing programmed cell death, influencing neural connectivity, and altering neurochemical profiles (De Vries and Simerly 2002). For example, gonadal hormones modulate serotonergic and $\gamma$-aminobutyric acid neurotransmission (Sumner and Fink 1998; McCarthy et al. 2002), promote the differentiation of vasopressin-expressing cells in the bed nucleus of the stria terminalis and medial amygdaloid 
nucleus (Wang et al. 1993), increase cell genesis in the developing hippocampus (Zhang et al. 2008), and interact with brain-derived neurotrophic factor to maintain dendritic length in the rat spinal nucleus of the bulbocavernosus (Yang et al. 2004; Rasika et al. 1999).

Secondly, it is now well-established that genes on the sex chromosomes are involved in sexual differentiation of the brain independent of gonadal steroid exposure. This was first suggested by studies showing sexual dimorphism in cultures of rat embryonic (E14) brain stem in the absence of sex steroids (Reisert and Pilgrim 1991), and later supported by elegant studies of mice in which sex chromosomes and gonadal sex were made independent by moving the $S R Y$ (testis determining) gene from the $\mathrm{Y}$ chromosome to an autosome (De Vries et al. 2002). Although most behavioral and anatomic differences were determined by the presence of ovaries or testes, some were dependent on chromosomes alone. For example, both male and female mice with $\mathrm{XY}$ sex chromosomes were more masculine (had a higher density of vasopressin-immunoreactive fibers) than $\mathrm{XX}$ mice in the lateral septum. Mice with a single $X$ chromosome $(39, \mathrm{X})$ can also be generated (Davies et al. 2005) and show altered cognition in specific domains such as fear reactivity and visuospatial attention (Davies and Wilkinson 2006).

However, it may not be appropriate to directly extrapolate the results of studies in rodents to humans. Two examples will demonstrate this difficulty. (1) In rodents, prenatal/neonatal testosterone produces many of its masculinizing effects after being aromatized to estrogen at the site of action. Masculinizing effects are thus, primarily, estrogen-receptor mediated. This is supported by experiments using mice in which estrogen agonists mimic testosterone effects on the sexual differentiation of behavior and experiments in which aromatase inhibitors and antiestrogens inhibit masculinization of behavior (Mccarthy 1994). In contrast, studies in the rhesus macaque suggest that the aromatization pathway is relatively unimportant in primates - estrogen agonists have limited masculinizing effects whereas the administration of a non-aromatizable testosterone, dihydrotestosterone, exerts similar effects to aromatizable testosterone (see Thornton et al. 2009 for review). It is generally accepted that gonadal steroidmediated sexual differentiation of the brain in humans relies primarily on the androgen rather than the estrogen receptor. This is supported by studies showing that $46, \mathrm{XY}$ humans lacking a functioning androgen receptor (complete androgen insensitivity syndrome) exhibit feminine behavior (Hines 2002) while 46,XY humans with a dysfunctional aromatase enzyme or those lacking a functioning estrogen receptor exhibit masculine behavior (Grumbach and Auchus 1999). (2) 45,X mice show no prenatal lethality, appear anatomically normal, and are fertile (Ashworth et al.
1991). The phenotype in 45, $\mathrm{X}$ humans is markedly different. Only $1 \%$ of human conceptuses with $\mathrm{X}$ monosomy survive to birth, and those that do exhibit a complex phenotype including short stature, gonadal failure, and other problems. During evolution, a pseudoautosomal region (PAR) on the short arm of the ancestral $\mathrm{X}$ chromosome has been retained in humans while most of its genes have been lost or moved to autosomes in rodents (Ross et al. 2005), contributing to the different phenotypes in mice and humans with 45,X karyotypes. This review will focus on the opportunities and challenges associated with studying brain development and neurodevelopmental disorders in individuals with loss of a sex chromosome.

\section{What is Turner syndrome?}

TS results from the complete loss of a sex chromosome (45, $\mathrm{X}$ ) or partial loss of the $\mathrm{X}$ chromosome that includes the distal tip of its short arm. TS occurs in approximately 1 in 1,900 live female births, making it one of the most common human chromosomal abnormalities (Nielsen and Wohlert 1991; Jacobs et al. 1974). Most individuals with TS have short stature and gonadal dysfunction, and are at increased risk for other problems such as structural cardiac and renal defects, autoimmune disease, and learning disabilities. There is a broad phenotype in TS, some of which is explained by mosaicism. Mosaic individuals possess a 45,X cell line and one or more additional cell lines. Most commonly the additional cell line contains one normal X and one structurally abnormal $\mathrm{X}$ or $\mathrm{Y}$ chromosome, but it may be a normal 46,XX or 46,XY cell line (Savendahl and Davenport 2000). Loss of ovarian function begins prenatally in TS, resulting in a postnatal developmental hormonal milieu that is estrogen and androgen deficient. Therefore, TS represents a powerful model for investigating both $\mathrm{X}$ chromosome and gonadal steroid effects.

For many years, research on TS has primarily focused on key medical issues, such as short stature and pubertal delay. Only recently, have families and physicians caring for these children begun to realize the major impact that neurocognitive deficits have on their overall success and happiness (Boman et al. 2004; Saenger et al. 2001). With this realization comes a need for a better understanding of brain structure and function in individuals with TS.

\section{The cognitive phenotype(s)}

The majority of individuals with TS are of normal intelligence, but they may show an uneven pattern of cognitive strengths and weaknesses. Areas which often present difficulties include higher-order visual-spatial func- 
tions, visual memory, visuo-constructive abilities, and visual attention, arithmetical abilities, executive functioning (particularly inhibitory control, auditory attention, and planning), social interaction, understanding facial expression, and specific aspects of language (verbal fluency, complex syntactic knowledge, and articulation). There are also areas of preserved and even strengthened function including specific aspects of language (word knowledge, receptive and expressive abilities, and verbal memory) and rote memory (Rovet 2004; Ross et al. 2006; Christopoulos et al. 2008).

Particularly relevant to the current discussion, females with TS are at an increased risk for certain neurodevelopmental disorders. In one study, autism was observed in five out of 150 individuals with TS (a rate of 3\%) (Creswell and Skuse 1999). Notably, this sample was recruited through a national survey of TS and excluded individuals who had been referred specifically for learning difficulties or behavioral problems (including autistic behavior). At the time this observation was published in the 1990s, the prevalence of autism in the normal female population was thought to be 1:10,000 (Lord et al. 1982), but it is now estimated at 4:10,000 (Chakrabarti and Fombonne 2001; Fombonne 2005; Baird et al. 2006), giving individuals with TS a 75 -fold increased risk of autism. ADHD was observed in $24 \%$ of school-aged girls with TS which represents an 18 -fold increase compared with girls in the general population (prevalence of 1.3\%) (Russell et al. 2006). There may also be an increased risk for schizophrenia. There are several published case reports (Kawanishi et al. 1997; Roser and Kawohl 2010) and TS occurs threefold more frequently in schizophrenic females than in the general female population (Prior et al. 2000). However, a population-based screening study with sufficient power to detect a relative risk of $>2.4$ for schizophrenia did not reveal such a relationship (Mors et al. 2001). Finally, despite the fact that most individuals with TS are of average intelligence, one university center reported intellectual disability in $11 \%$ of the 500 individuals with TS followed in their clinic (Sybert and McCauley 2004). This is a 14fold increase when compared with the CDC estimated population incidence of $0.8 \%$.

\section{Brain phenotype(s)}

The cognitive phenotype(s) observed in individuals with TS are assumed to reflect changes in neurobiological systems which serve multiple functional domains. The results of structural and functional neuroimaging studies in individuals with TS are consistent with this view. The most consistently reported findings are a reduction in the volume of the parietal lobe and an increase in the volume of the amygdala (Cutter et al. 2006; Kesler et al. 2004; Molko et al. 2004). The parietal lobe is involved in mental rotation of objects, executive function, attention, and working memory, domains which are often impaired in individuals with TS. Functional imaging studies using positron emission tomography have reported reduced activation in parietal regions at rest (Elliott et al. 1996), and functional magnetic resonance imaging studies have shown abnormal engagement of parietal and prefrontal areas during specific tasks in females with TS (Haberecht et al. 2001; Molko et al. 2003; Hart et al. 2006; Kesler et al. 2006; Beaton et al. 2010). Diffusion tensor imaging (DTI) has also revealed reduced fractional anisotropy, often interpreted as reduced structural integrity, in the superior longitudinal fasciculus, a major fiber tract linking parietal and frontal regions and which includes the "where" pathway of visuospatial cognition. The "where" pathway appears to be more severely affected in TS than the "what" pathway which runs through the inferior longitudinal fasciculus (Holzapfel et al. 2006). The amygdala has been implicated in the recognition of emotions from facial expressions, with a particular role in processing fear, in the detection of gaze direction and eye contact, and in the mediation of arousal produced by affective stimuli. In one study of females with TS, poorer performance on a task of recognizing fearful facial expressions was correlated with increased activation in the right amygdala. In contrast, within control females poorer performance correlated strongly with reduced activation of the right and left amygdala (Skuse et al. 2005). Other brain regions where volume decreases in TS have been reported include occipital white matter, hippocampus, and thalamus. Volume increases have been reported in the cerebellar gray matter, orbitofrontal cortex, and superior and middle temporal lobes (Cutter et al. 2006; Kesler et al. 2004). An MR spectroscopy study of the temporal lobe suggests the increase is the result of a developmental failure to prune neurons (Rae et al. 2004).

While TS is a clearly defined genetic syndrome, there are several different mechanisms which appear to contribute to the cognitive and brain phenotypes which have been observed. These include gonadal steroid deficiency, haploinsufficiency of genes on the $\mathrm{X}$ chromosome, failure to express imprinted genes (that is genes expressed from a chromosome derived from one parent and not the other), and the uncovering of $\mathrm{X}$ chromosome mutations (i.e., $\mathrm{X}$ linked recessive inheritance). We will explore these mechanisms next.

\section{Mechanisms: gonadal steroid effects}

The majority of females with TS have gonadal insufficiency (Pasquino et al. 1997) and require exogenous sex steroids 
for induction of puberty. By observing whether sex steroid replacement therapy rescues any of the TS cognitive or brain phenotypes, the importance of sex steroids in the TS phenotype can begin to be defined. Romans et al. (1998) reported that performance on the Lafayette Pegboard (Haaland and Delaney 1981), a motor planning task, was better in older girls with TS (ages 17-22 years) compared with adolescents (ages 13-16 years). They postulated that the improvement could be the result of the cumulative effects of estrogen replacement therapy. However, all study subjects were estrogen treated, so a direct cause-effect relationship could not be established.

More direct evidence for the positive effects of estrogen therapy on brain function come from a placebo-controlled, double-blind study of the effects of estrogen and/or growth hormone $(\mathrm{GH})$ on final adult height in TS. Girls with TS were eligible to start the study between the ages of 5 and 11 years. They were randomly assigned to one of four treatment groups: estrogen (ethinyl estradiol, $25 \mathrm{ng} \mathrm{kg}^{-1}$ day $^{-1}$, by mouth for girls ages 5-8 years; $50 \mathrm{ng} \mathrm{kg}^{-1}$ day $^{-1}$ for girls ages 812), GH $0.1 \mathrm{mg} / \mathrm{kg}$, three times weekly, subcutaneously, the combination of estrogen and $\mathrm{GH}$, or placebo. All subjects received an oral and an injected medication/ placebo. In the first study using this sample, cognition was tested on 30 placebo-treated and 24 estrogen-treated TS girls on one occasion at an average age of $8.1 \pm 0.6$ years after an average of $2.1 \pm 0.9$ years (range, $0.5-3$ years) in the study (Ross et al. 2000a). About half of the children were receiving $\mathrm{GH}$, however, no significant interaction effects for estrogen and GH were found. Therefore, the $2 \times$ 2 factorial design was merged into an estrogen-yes versus estrogen-no comparison. A locally recruited age-matched control group of 29 girls was also tested. As expected, performance, but not verbal, IQ was significantly higher in the controls than in either TS group. The estrogen-treated TS group performed better than the placebo-treated TS group on two tests of verbal memory (Children's Word List immediate and delayed recall (Tucker et al. 1974); $p=$ 0.01 and 0.04 ) and one test of nonverbal memory (Digit Span backwards (Wechsler 1974); $p=0.02$ ), although the results were not significant after adjusting for multiple comparisons. Performance on these tests was similar for the estrogen-treated TS group and the control group.

In a second study, cognitive and motor functions were tested in 23 placebo-treated and 24 estrogen-treated girls with TS at an average age of $11.9 \pm 0.5$ years after an average of $4.0 \pm 2.1$ years, and compared with 41 control girls (Ross et al. 1998). Tests for general cognitive ability, motor function, and handedness, nonverbal tasks for measurement of processing speed, and behavior questionnaires were given. Performance IQ was significantly higher in the control group. The speed of performance was improved by estrogen treatment in TS subjects, although the accuracy of timed spatial tasks was not consistently changed. Estrogen was demonstrated to have a significant positive effect on nonverbal processing speed (sum of times required for motor-free visual perception test (Colarusso and Hammill 1996), test of facial recognition (Benton et al. 1983), Money street map (Money et al. 1965), and matching familiar figures (Kagan 1966)) and selective aspects of speeded motor performance such as the Lafayette pegboard (Haaland and Delaney 1981).

In 2002, Ross et al. (2002) compared cognitive function of adult women with TS who were receiving estrogen replacement therapy (e.g., estrogen and progesterone sequentially and oral contraceptives) or who had apparently normal ovarian function (as demonstrated by normal menstrual cycles and adult breast development) with a group of control women. The women with TS performed more poorly than controls on measures of spatial/perceptual skills (including gestalt closure (Kaufman 1983) and visual object and space perception silhouettes (Warrington and James 1991)), visual-motor integration (including Beery visual-motor integration (Beery 1989) and Rey-copy (Denman 1984; Waber and Holmes 1985)), affect recognition (Borod et al. 1990), visual memory (including Reyimmediate and delayed recall (Denman 1984; Waber and Holmes 1985), WMS-R (Wechsler 1987), and Warrington Faces (Warrington 1984)), attention (TOVA (McCarney 1990) — \% commission errors), and executive function (Rey Figure Organization (Waber and Holmes 1985)) despite estrogen replacement therapy or presence of normal menses. Based on these results they argued that the core cognitive phenotype in TS is mediated by direct $\mathrm{X}$ chromosome effects rather than sex steroid effects. However, there was not an untreated TS control group and age at initiation of sex hormone therapy, mode of therapy, and adequacy of therapy were not reported. Sex steroids can have both organizational effects (that is permanent changes to the neural substrate, usually occurring early in development) and activational effects (transient changes, usually occurring later in life). Until recently, initiation of estrogen therapy was often delayed until age 15 years or later in an effort to maximize height. If the women in this study did not receive early estrogen replacement, the study cannot rule out a role for organizational effects of estrogen in early puberty or childhood. In addition, the predominant estrogen "replacement therapy" in the USA has been conjugated equine estrogens, which contains many estrogens, some of which are not normally found in humans. It remains to be determined if the positive effects of estrogen reported for the children in the above studies or in children who receive more physiologic estrogen replacement therapies will impact cognitive and motor function in adulthood. 
Girls with TS have often been treated with oxandrolone, a non-aromatizable androgen, to accelerate linear growth. Ross et al. (2003) randomized TS girls, ages 10-14, to receive oxandrolone or placebo for 2 years. Four cognitive domains were evaluated (verbal abilities, spatial cognition, executive function, and working memory) at baseline, 1, and 2 years of the study. Three of the four domains studied did not differ between the groups. However, verbal working memory was better in the oxandrolone-treated group. A similar result was observed in a randomized, double-blind, placebo-controlled study of oral methyl testosterone treatment for 1 year in TS women between 17 and 27 years of age. Methyl testosterone improved verbal memory as well as attention and reaction time, but did not affect spatial cognition or executive function (Zuckerman-Levin et al. 2009). Oxandrolone has also been reported to reduce problem behavior (as measured by the Child Behavior Checklist (Achenbach 1991)) in girls in which mean age at initiation was 10 years and mean age at discontinuation was 15 years (Menke et al. 2010).

Absent from the current research literature are studies on the possible effects of prepubertal gonadal steroid deficiency in girls with TS. Little definitive data on sex steroid regulation in prepubertal children has been established due to the absence of sensitive, commercially available assays. Klein et al. (1994), using a highly sensitive bioassay, were the first to determine that estrogen levels in prepubertal girls are significantly higher than those of prepubertal boys. Recently, however, sensitive, very specific, and highly reproducible assays for estradiol and other sex steroids using gas chromatography combined with mass spectrometry or liquid chromatography tandem mass spectrometry (LC-MS/MS) methodologies have become commercially available. These assays are currently considered the gold standard for sex steroid measurements (Albrecht and Styne 2007; Rahhal et al. 2008).

Recently, LC-MS/MS was used to compare multiple sex steroids, including estradiol, in the serum of prepubertal boys and girls ages $6-11.5$ years. $17-\beta$ estradiol levels in prepubertal boys were undetectable or extremely low (median, $\leq 3.7 \mathrm{pmol} / \mathrm{l}$ ), whereas levels in prepubertal girls were significantly higher (median, $9.6 \mathrm{pmol} / \mathrm{l}$ ) (Courant et al. 2010). While estrogen levels have not been directly measured in young girls with TS, one would expect the majority to be estrogen deficient because of early, accelerated follicular degeneration, an assumption which is supported by markedly elevated FSH levels in most young girls with TS (Fechner et al. 2006).

Also lacking in the research literature are MRI studies directly investigating the role of estrogen or androgen on the brain in TS. Only one study has addressed effects of androgen supplementation on the brain. Cutter et al. (2006) reported no differences in brain structure between 12 women who received oxandrolone and 15 who did not, using a voxel-based morphometry method. No MRI studies have assessed estrogen effects on the brain in TS. Assessing estrogen effects on the brain is complicated by the multitude of estrogen replacement regimens, including the form of estrogen, mode of delivery, timing of initiation, timing of dose acceleration, and addition of progestational agents. Finally, no studies have assessed the impact of sex steroid hormone replacement on psychiatric diagnosis or severity of symptoms in those subgroups of TS females diagnosed with ASC, intellectual disability (ID), ADHD, or schizophrenia. It is of particular interest to note that three randomized double-blind placebo-controlled trials and one open-label study have shown that giving estradiol in addition to traditional antipsychotic medications is associated with significant reduction of symptoms in women with schizophrenia (Kulkarni 2009). Thus, it is plausible that estrogen deficiency could increase the risk for schizophrenia in women with TS. One of the most marked sex differences in the general population of individuals with schizophrenia is a later age of onset in females than in males, and it has been hypothesized that this is the result of the protective actions of estrogen. If this is the case, risk for schizophrenia within the TS population could vary with age at initiation of estrogen therapy.

\section{Mechanisms: haploinsufficiency of X chromosome genes}

Although typical females have two $\mathrm{X}$ chromosomes, only one of these is generally active. $\mathrm{X}$ chromosome inactivation (the process by which one $\mathrm{X}$ is suppressed while the other remains active) acts to negate the "dosage" difference in $\mathrm{X}$ chromosome genes between males and females. However, some genes on the human $\mathrm{X}$ chromosome continue to be expressed from the "inactive" X. It has been estimated that 15-20\% of genes are expressed from the inactive X (Craig et al. 2004; Carrel and Willard 2005), although a recent gene expression study suggested that only $5 \%$ of X-linked genes actually achieve significantly higher expression levels in females compared with males (Johnston et al. 2008). For the subset of $X$ chromosome genes that escape inactivation, females with TS will be haploinsufficient and this may contribute to the cognitive phenotype and risk for other neurodevelopmental disorders. One approach to identify the particular genes involved is to compare phenotypes of individuals missing various portions of one sex chromosome, a strategy known as deletion mapping. Ross et al. (2000b) and Zinn et al. (2007) used this approach. For their phenotype of interest, they developed a "Turner Syndrome Cognitive Summary Score" or TSCS, which was based on discriminant function analysis of a wide range of cognitive tests. While working memory, 
attention-impulse control, and executive function tests are included, the final score is heavily weighted towards visuospatial abilities. Results from their initial study, which included both children and adults and used TSCS score as a binary variable, suggested that Xp22.3 contains one or more genes that influence TSCS (Ross et al. 2000b). A subsequent study which focused only on adults and used TSCS as a quantitative variable confirmed that deletion of Xp22.3 was sufficient to cause this neurocognitive phenotype (Zinn et al. 2007). This region contains 31 annotated genes and the authors highlighted two genes, STS and NLGN4X as potential candidates. STS has been implicated in $\mathrm{GABA}_{\mathrm{A}}$ receptor function (Majewska 1992) and visuospatial attention in a mouse model of TS (Davies et al. 2007) and has also been linked to ADHD in humans (Doherty et al. 2003; Kent et al. 2008; Brookes et al. 2008). NLGN4X mutations have been associated with ASC and X-linked ID (Chakrabarti et al. 2009; Daoud et al. 2009; Jamain et al. 2003; Laumonnier et al. 2004; Lawson-Yuen et al. 2008; Talebizadeh et al. 2006; Yan et al. 2005; Qi et al. 2009). However, it should be noted that the smallest deletion associated with the neurocognitive phenotype did not include either of these genes, but only PLCXD1, GTPBP6, PPP2R3B, and SHOX, none of which have been previously implicated in cognition or risk for neurodevelopmental disorders.

A similar strategy was applied by Good et al. (2003) to explore the cause of decreased recognition of fear in females with TS. A genetic locus (no greater than $4.96 \mathrm{Mb}$ in size) was identified at Xp11.3 that affected fear recognition and amygdala volume. The authors hypothesized that the genes for monoamine oxidase $\mathrm{A}(M A O A)$ and $\mathrm{B}(M A O B)$, which are located in this region and are involved in the oxidative deamination of several neurotransmitters, including dopamine and serotonin, could be responsible for the phenotype. Subsequently, this group used regression-based association mapping to identify potential candidate genes within this region. They reported a single-nucleotide polymorphism in EFHC2 which explained over $13 \%$ of the variation in fear recognition within women with TS (Weiss et al. 2007). However, a later study by a separate lab failed to replicate this finding (Zinn et al. 2008).

In conclusion, haploinsufficiency of $\mathrm{X}$ chromosome genes is likely to play a role in the cognitive phenotype of TS. While several interesting candidate genes have been proposed, no genes have been conclusively identified as responsible for any aspect of the cognitive phenotype.

\section{Mechanisms: failure to express parentally imprinted genes}

Genomic imprinting refers to a process by which genetic effects are influenced according the whether the genes are transmitted through the father or the mother (Skuse 2000). Ordinarily this would not result in sex differences, but it will do so if the imprinting affects the $\mathrm{X}$ chromosome. This possibility has been most extensively studied in relation to social and communicative impairment in TS. In 1997, Skuse et al. reported that social difficulties were more pronounced in females with TS who inherited a maternal X chromosome than in those who inherited a paternal $\mathrm{X}$ chromosome. Typical females inherit an $\mathrm{X}$ chromosome from both parents $\left(\mathrm{X}^{\mathrm{p}} \mathrm{X}^{\mathrm{m}}\right)$, and typical males inherit only a maternal $\mathrm{X}\left(\mathrm{X}^{\mathrm{m}} \mathrm{Y}\right)$. The authors hypothesized that a gene expressed on the paternal $\mathrm{X}$ enhances social cognition and is a protective factor against ASC (Skuse et al. 1997). Shortly afterwards, Creswell and Skuse reported five cases of autism from an unselected sample of 150 subjects with TS (Creswell and Skuse 1999). All the affected cases were $\mathrm{X}^{\mathrm{m}}$ or had a structurally abnormal paternal $\mathrm{X}$. While this was certainly an exciting finding, it should be kept in mind that $77 \%$ of TS females are $\mathrm{X}^{\mathrm{m}}$, while only $23 \%$ are $\mathrm{X}^{\mathrm{p}}$, meaning that by chance alone one would expect to find autism in association with $\mathrm{X}^{\mathrm{m}}$ more often than with $\mathrm{X}^{\mathrm{p}}$. In addition, all of the autism cases in that report had low verbal IQ scores, despite the fact that intelligence is usually in the average range in TS, raising the possibility that the autism was secondary to ID. The male-to-female sex ratio for ASC is only 2:1 in individuals with moderate to severe ID in contrast to 5.5:1 in individuals with average intelligence (Fombonne 2005). It is also notable that some of the autism cases had a structurally abnormal paternal $X$. TS individuals with small ring $X$ chromosomes often have a severe phenotype that is not typical of TS and includes intellectual disability. In these individuals, the loss of the XIST gene, which is involved in causing $\mathrm{X}$ inactivation, may allow for normally inactivated genes to be expressed, resulting in functional disomy (Kubota et al. 2002). Finally, Henn and Zhang (1997) raised the possibility that the presence of residual $\mathrm{Y}$ chromosome sequences in a subset of cells in the brain could explain the greater vulnerability of $\mathrm{X}^{\mathrm{m}} \mathrm{TS}$ females to social dysfunction, but this hypothesis is untestable without access to brain tissue.

Despite many uncertainties, the role of parentally imprinted genes in TS and in sex-biased neurodevelopmental disorders is an extremely exciting avenue for future research. Imprinting effects are now routinely tested for in MRI studies in individuals with TS and have been observed for the superior temporal gyrus (Kesler et al. 2003), occipital white matter, cerebellar gray matter (Brown et al. 2002), hippocampus, thalamus, and caudate (Cutter et al. 2006). Imprinting effects have also been reported for nonbehavioral aspects of the TS phenotype, including body mass index, lipid levels, kidney malformations, and ocular abnormalities (Sagi et al. 2007). 


\section{Mechanisms: $X$-linked recessive inheritance and functional disomy}

Like typical males, females with TS are at an increased risk of $\mathrm{X}$-linked recessive conditions, including ID, as a second $\mathrm{X}$ is not present to balance the effects of the abnormal gene. In the general population, more than $10 \%$ of cases of ID show an Xlinked pattern of inheritance, involving mutations in over 90 different genes. On the flip side, the subgroup of individuals with TS at highest risk for ID are those with small ring Xs that fail to undergo inactivation, resulting in functional disomy for normally inactivated genes (Kubota et al. 2002). Intriguingly, some X-linked recessive conditions may result in the loss of the diseased $\mathrm{X}$ during mitosis, producing mosaic TS. This has recently been reported for female embryos carrying the full fragile X mutation (Dobkin et al. 2009).

\section{Future directions: deeper into the brain}

While neuroimaging has and will continue to advance our understanding of neurodevelopment in individuals with TS, current techniques are not capable of identifying the neurodevelopmental processes which underlie observed changes in tissue volumes or DTI parameters. Structural and molecular biology techniques applied to post-mortem brains complement neuroimaging approaches by identifying alterations in the number or volume of different cell types and alterations of pathway-related genes and proteins (Schmitt et al. 2008). Unfortunately, post-mortem studies in individuals with TS are extremely scarce and date back several decades. Based on the limited studies available, there appears to be overall decreased cortical organization, possibly due to neuronal migration deficits (Molland and Purcell 1975; Gullotta and Rehder 1974; Urich 1979; Reskenielsen et al. 1982). Significantly, more information could be gained from postmortem samples given technical advances and the development of more targeted hypotheses. For example, the frequency of cell line mosaicism and differences in gene expression within specific regions of the brain could be determined. Comparison to post-mortem findings in other neurodevelopmental conditions could clarify whether there is true etiological homology between conditions or if very different mechanisms produce similar behavioral outcomes. Brain banks play an important role in psychiatric research, particularly in the schizophrenia field, and it worth considering whether this strategy can be applied in the study of TS.

\section{Future directions: deeper into the genome}

One of the most striking features of the TS population is the extreme variability in phenotype. We have already dis- cussed some genetic aspects of TS that may help explain this variability, including parental origin of $\mathrm{X}$ chromosome, cell line mosaicism, imprinting, and the uncovering of Xlinked mutations. Variability could also result from the genetic background in which loss of the second sex chromosome occurs. Applying genome-wide analysis approaches to individuals with TS and comparing those with or without comorbid neurodevelopmental disorders could be a powerful strategy for identifying genetic risk factors on the autosomes, although limited sample sizes would be a definite issue. An alternative approach would be to select candidate genes which have emerged from genome-wide studies of relevant neurodevelopmental disorders and investigate these intensively within TS samples. For example, mutations in genes coding for synaptic cell adhesion molecules and their related proteins, such as neurexin-1 (NRXN1) and contactin-associated protein-like 2 (CNTNAP2), have been reported in association with ASC (Feng et al. 2006; Szatmari et al. 2007; Kim et al. 2008; Bakkaloglu et al. 2008; Rossi et al. 2008), schizophrenia (Kirov et al. 2008; Walsh et al. 2008; Rujescu et al. 2009; Stone et al. 2008; Kirov et al. 2009; Need et al. 2009; Friedman et al. 2008), ADHD (Elia et al. 2010), and ID (Friedman et al. 2008; Zweier et al. 2009). Genetic and epigenetic changes on the remaining $\mathrm{X}$ could also contribute to phenotypic variability, with some individuals capable of compensating for the lost alleles by upregulating the remaining ones. X chromosome genes including NLGN4, NLGN3, MECP2, and PTCHD1 have been linked to ASC (Daoud et al. 2009; Jamain et al. 2003; Laumonnier et al. 2004; Lawson-Yuen et al. 2008; Talebizadeh et al. 2006; Yan et al. 2005; Pinto et al. 2010; Noor et al. 2010; Shinawi et al. 2009; Carney et al. 2003; Lam et al. 2000) and would be worthy of detailed investigation in TS. Intriguingly, postsynaptic neuroligins (which include NLGN4 and NLGN3) interact with the presynaptic neurexins (such as NRXN1) to form trans-synaptic associations. Both groups are required for the maturation of glutamatergic excitatory and GABAergic inhibitory synapses (Leone et al. 2010). We have already stated the potential value of post-mortem gene expression studies in brain, but similar approaches in more accessible tissues would also be of interest.

\section{Future directions: going earlier in development}

The majority of neuroimaging and behavioral studies of TS carried out to date have focused on older children and adults. Thus, they cannot address when in development the reported differences emerge. A better knowledge of when brain development is altered could help pinpoint the cause of functional changes and identify critical periods for intervention. In addition, older children and adults have 
often been exposed to many years of therapies such as GH and estrogen that are likely to impact neurodevelopment. Treatment may have produced some of the observed neural differences or it may have minimized or eliminated neural differences present before treatment began. It is now recommended that GH therapy (used to improve or normalize height) be considered as soon as growth failure is demonstrated. In the recent "Toddler Turner Study" study, girls ages 9 months to 4 years with TS (mean age= 2 years) were randomized to GH therapy or no therapy. Girls in the GH group achieved a height 1.6 SD above that of the no therapy group after 2 years, and averaged just 0.3 SD below the mean height for girls in the general population (Davenport et al. 2007). Since growth failure typically begins in infancy, many girls with TS are now being treated with GH beginning in the first 2 years of life. However, the effect of GH on brain development in young children is unknown. Estrogen therapy is now delayed until the time of normal puberty and the effect of estrogen on brain development in the first few years of life is unknown. Studies of brain development in TS, prior to long-term hormonal therapy, will be critical in determining the potential role of standard hormone therapies in ameliorating or producing the brain changes observed in older females with TS. This information will have important implications for determining appropriate timing, type, and dosage of hormone therapies.

At present, the only neurocognitive and psychosocial data for this group comes from the Lilly "Toddler Turner Study" in which young girls with TS were followed at 4 months intervals for 2 years. At baseline, 1 , and 2 years neurocognitive and psychosocial studies were performed. On the Mullen Scale of Early Learning (Mullen 1995), this TS population was significantly below the normative means for the five subtests (Fine-Motor, Gross Motor, Receptive Language, Expressive Language, and Visual Reception), with approximately $20 \%$ of the sample being more than 2SDs below the mean on the overall score. On a measure of social-behavioral functioning, the Vineland SocialEmotional Early Scales (Sparrow and Balla 1998), the TS group fell largely at the lower end of the average range of functioning, with the scores for Interpersonal Relationships, Play and Leisure, and the Composite being significantly below the normative means. On the Carey Temperament Scale (Carey and McDevitt 1995), the girls with TS were described as less persistent, more cautious in their approach to new situations, and slower to adapt to these situations (Hooper et al. 2005). The same study provides preliminary evidence that the trajectory of brain development in girls with TS from birth to 2 years of age may be considerably different that those of typical females. They compared historical birth length, weight and head circumference (HC) values corrected for gestational age $<37$ weeks to those measured at study entry. While mean length and weight fell markedly from birth to study entry $(\sim 1 \mathrm{SD})$, mean $\mathrm{HC}$ was relatively smaller at birth $(-1.0 \pm 1.2 \mathrm{SD})$ and normalized by study entry $(-0.0 \pm 1.2 \mathrm{SD})$, suggesting accelerated brain growth in early life (Davenport et al. 2002). Interestingly, an accelerated increase in HC in the first year of life has also been reported for children with autism (Hazlett et al. 2005).

\section{Future directions: addressing the role of clinical experience and treatment on neurodevelopmental outcome}

The effects of $\mathrm{X}$ chromosome monosomy is not restricted to the brain, but impacts almost every organ system in the body. Therefore, individuals with TS may be exposed to a wide range of medical issues and treatment paradigms which could potentially affect neurodevelopment. Despite this reality, it is unusual for published studies of cognition, behavior, or neuroimaging in individuals with TS to include detailed information on the medical history of the participants. In this review, we will highlight four common medical issues in this population and how they might impact brain development. These include growth failure (and subsequent treatment with $\mathrm{GH}$ ), cardiovascular malformations (and related surgeries), thyroid autoimmunity, and hearing issues.

Short stature is the most common physical finding in TS, with untreated individuals achieving an average adult stature of $20 \mathrm{~cm}(8 \mathrm{in}$.) shorter than would be predicted based on parental height (Ranke and Grauer 1994). Growth failure results from haploinsufficiency of the short-stature homeobox-containing gene which belongs to a family of homeobox genes, critical transcriptional regulators of early development (Rao et al. 1997). Psychosocial functioning in girls with TS does not appear to be strongly related to stature, despite concerns that short stature may result in stigmatization, juvenilization, and decreased quality of life (QOL) (Sandberg and Voss 2002). The standard treatment for growth failure is the administration of supraphysiological doses of GH (Davenport 2006) However, the reported impact of GH on QOL has been relatively unimpressive. For example, Amundson et al. (2010) recently reported that in a group of 111 adults with TS, previous GH treatment was associated with less pain but did not mitigate the increased social isolation of this group. GH could have a direct effect on brain development, especially in younger children. Information regarding the impact of circulating $\mathrm{GH}$ levels and of GH supplementation in particular on human structural brain development is extremely limited, but a direct effect of circulating GH on brain structure is possible, given that $\mathrm{GH}$ is found in the brain and CSF and 
$\mathrm{GH}$ receptors are located in multiple brain regions including the choroid plexus, hippocampus, hypothalamus, amygdala, and pituitary (Nyberg 2000). Circulating GH does not passively diffuse across the blood-brain barrier (BBB), but it may be transported across the $\mathrm{BBB}$ via a receptor-mediated mechanism (Coculescu 1999). GH may also exert effects on brain development via insulin-like growth factor 1 (IGF-1), which appears to be actively transported across the BBB (Gunnell et al. 2005). IGF-1 receptors are also present in the brain with the greatest density of receptors localized to the cortex and hippocampus (Adem et al. 1989). Rodent studies demonstrate that IGF-1 plays a crucial role in neurogenesis, myelination, synaptogenesis, and dendritic branching. Transgenic mice which overexpress IGF-1 have increased brain size, while those with IGF-1 deletions have reduced brain size (Carson et al. 1993; Beck et al. 1995). Thus far only one structural MRI study in TS has addressed this issue. Cutter et al. (2006) reported that adult women with TS who did not use $\mathrm{GH}$ had significantly decreased gray matter volume bilaterally in the parieto-occipital and posterior temporal lobes and basal ganglia, compared with those who did not take $\mathrm{GH}$.

Cardiovascular malformations are common in individuals with TS. In an echocardiographic study of 200 individuals, aortic coarctation with or without a bicuspid valve was present in $14 \%$, bicuspid valve alone in $10 \%$, aortic stenosis and/or regurgitation in 5\%, and other structural defects such as hypoplastic left heart, atrial septal defect, and ventricular septal defect in $10 \%$ (Sybert 1998). Such malformations represent an independent risk factor for altered brain development. Newborns with congenital heart disease (CHD) show a high frequency of acquired white matter injury. Significant problems pertaining to intelligence, neuropsychological development, and social cognition (Bellinger 2008) have been documented for many children with CHD who have undergone surgery. Neurobehavioral and neurological abnormalities are also common in children with CHD prior to surgery (McQuillen and Miller 2010) and may result from the same developmental event(s) that caused the cardiac defect or from damage incurred prenatally from altered blood flow or oxygenation. For example, coarctation/aortic arch hypoplasia increases the risk for microcephaly at birth 2.8-fold.

Individuals with TS are at increased risk for autoimmune disorders and the risk increases with age (Mortensen et al. 2009). Thyroiditis is the most common autoimmune disorder and has been reported as early as 4 years of age. In a study of 84 children with TS who were followed longitudinally for an average of 8 years, 20 developed hypothyroidism and two developed hyperthyroidism (Livadas et al. 2005). Hypothyroidism has profound effects on neurodevelopment and may have more subtle effects when present subclinically or transiently (Williams 2008).

Sixty to $80 \%$ of individuals with TS suffer from conductive hearing loss because of chronic otitis media (Hultcrantz 2003). This may be related to having a short, horizontally oriented eustachian tube which results in poor drainage and ventilation of the middle ear space. Ear infections are especially common in the first few years of life. For example, in the "Toddler Turner Study", at the baseline study visit (mean age $=2$ years), 26\% had tympanostomy tubes present, another $64 \%$ had evidence of abnormal middle ear function, and $27 \%$ had abnormal hearing in one or both ears (Davenport et al. 2010). In addition, progressive sensorineural hearing loss with a unique dip in the $1.5-2 \mathrm{kHz}$ region and/or a high frequency loss (above $8 \mathrm{kHz}$ ) may present very early and necessitate the use of hearing aids in childhood. Early hearing difficulties could clearly impact the development of language and socialization and should be documented in research studies as well as dealt with quickly in the clinic.

\section{Conclusions}

Turner syndrome is one of the most common sex chromosome abnormalities and as such represents an important health problem. In addition, studies carried out in this population can help us model the effects of both sex hormones and genes on the $\mathrm{X}$ chromosome in early brain development and thereby better our understanding of the differential vulnerability to and expression of neurodevelopmental disorders in males and females. This research paradigm has already produced novel theories, such as the $\mathrm{X}$-linked parental imprinting theory of autism. However, disentangling the contribution of steroid hormones and genetic factors is challenging. We suggest several directions for future research to help resolve these issues including carrying out neuroimaging studies at earlier time-points, pursuing post-mortem studies with the latest structural and molecular biology techniques, applying modern genomics strategies, and the routine consideration and reporting of medical history.

Acknowledgment RK is supported by a K01 Mentored Research Scientist Development Award from the NIMH (MH083045).

\section{References}

Achenbach TM. Manual for the Child Behavior Checklist and 1991 Profile. Burlington: University of Vermont Department of Psychiatry; 1991. 
Adem A, Jossan SS, Dargy R, Gillberg PG, Nordberg A, Winblad B, et al. Insulin-like growth factor-I (Igf-1) receptors in the human brain - quantitative autoradiographic localization. Brain Res. 1989;503(2):299-303.

Albrecht L, Styne D. Laboratory testing of gonadal steroids in children. Pediatr Endocrinol Rev. 2007;5 Suppl 1:599-6097.

Amundson E, Boman UW, Barrenas ML, Bryman I, LandinWilhelmsen K. Impact of growth hormone therapy on quality of life in adults with Turner syndrome. J Clin Endocrinol Metab. 2010;95(3):1355-9.

Ashworth A, Rastan S, Lovellbadge R, Kay G. X-chromosome inactivation may explain the difference in viability of $\mathrm{XO}$ humans and mice. Nature. 1991;351(6325):406-8.

Baird G, Cox A, Charman T, Baron-Cohen S, Wheelwright S, Swettenham J, et al. A screening instrument for autism at 18 months of age: a six year follow-up study. J Am Acad Child Adolesc Psychiatry. 2000;39:694-702.

Baird G, Simonoff E, Pickles A, Chandler S, Loucas T, Meldrum D, et al. Prevalence of disorders of the autism spectrum in a population cohort of children in South Thames: the Special Needs and Autism Project (SNAP). Lancet. 2006;368(9531):210-5.

Bakkaloglu B, O'Roak BJ, Louvi A, Gupta AR, Abelson JE, Morgan $\mathrm{TM}$, et al. Molecular cytogenetic analysis and resequencing of contactin associated protein-like 2 in autism spectrum disorders. Am J Hum Genet. 2008;82(1):165-73.

Beaton EA, Stoddard J, Lai S, Lackey J, Shi JR, Ross JL, et al. Atypical functional brain activation during a multiple object tracking task in girls with Turner syndrome: neurocorrelates of reduced spatiotemporal resolution. Am J Intellect Dev Disabil. 2010;115(2):140-56.

Beck KD, Powellbraxton L, Widmer HR, Valverde J, Hefti F. Igf1 Gene disruption results in reduced brain size, CNS hypomyelination, and loss of hippocampal granule and striatal parvalbumincontaining neurons. Neuron. 1995;14(4):717-30.

Beery K. Development test of visual-motor integration: administration, scoring, and teaching manual, 3rd revision. Cleveland: Modern Curriculum Press; 1989.

Bellinger DC. Are children with congenital cardiac malformations at increased risk of deficits in social cognition? Cardiol Young. 2008;18(1):3-9.

Benton A, deS Hamsher K, Varney N, Spreen O. Facial recognition test. In: Contributions to Neuropsychological Assessment. New York: Oxford University Press; 1983

Boman UW, Bryman I, Moller A. Psychological well-being in women with Turner syndrome: somatic and social correlates. J Psychosom Obstet Gynecol. 2004;25(3-4):211-9.

Borod JC, Welkowitz J, Alpert M, Brozgold AZ, Martin C, Peselow E, et al. Parameters of emotional processing in neuropsychiatric disorders - conceptual issues and a battery of tests. J Commun Disord. 1990;23(4-5):247-71.

Brookes KJ, Hawi Z, Kirley A, Barry E, Gill M, Kent L. Association of the steroid sulfatase (STS) gene with attention deficit hyperactivity disorder. Am J Med Genet B Neuropsychiatr Genet. 2008;147B(8):1531-5.

Brown WE, Kesler SR, Eliez S, Warsofsy IS, Haberecht M, Patwardhan A, et al. Brain development in Turner syndrome: a magnetic resonance imaging study. Psychiatry Res. 2002;116:187-96

Carey W, McDevitt S. The Carey Temperament Scales. Scottsdale: Behavioral-Developmental Initiatives; 1995.

Carney RM, Wolpert CM, Ravan SA, Shahbazian M, Ashley-Koch A, Cuccaro ML, et al. Identification of $M E C P 2$ mutations in a series of females with autistic disorder. Pediatr Neurol. 2003;28(3):205-11.

Carrel L, Willard HF. X-inactivation profile reveals extensive variability in X-linked gene expression in females. Nature. 2005;434(7031):400-4
Carson MJ, Behringer RR, Brinster RL, Mcmorris FA. Insulin-like growth factor-I increases brain growth and central-nervoussystem myelination in transgenic mice. Neuron. 1993;10 (4):729-40.

Chakrabarti S, Fombonne E. Pervasive developmental disorders in preschool children. J Am Med Assoc. 2001;285:3093-9.

Chakrabarti B, Dudbridge F, Kent L, Wheelwright S, Hill-Cawthorne G, Allison $\mathrm{C}$, et al. Genes related to sex steroids, neural growth, and social-emotional behavior are associated with autistic traits, empathy, and Asperger syndrome. Autism Res. 2009;2(3):157-77.

Christopoulos P, Deligeoroglou E, Laggari V, Christogiorgos S, Creatsas G. Psychological and behavioural aspects of patients with Turner syndrome from childhood to adulthood: a review of the clinical literature. J Psychosom Obstet Gynecol. 2008;29 (1):45-51.

Coculescu M. Blood-brain barrier for human growth hormone and insulin-like growth factor-I. J Pediatr Endocrinol Metab. 1999;12 (2): $113-24$.

Colarusso R, Hammill D. Motor-free Visual Perception Test-revised manual. Novato: Academic Therapy; 1996.

Courant F, Aksglaede L, Antignac JP, Monteau F, Sorensen K, Andersson AM, et al. Assessment of circulating sex steroid levels in prepubertal and pubertal boys and girls by a novel ultrasensitive gas chromatography-tandem mass spectrometry method. J Clin Endocrinol Metab. 2010;95(1):82-92.

Craig IW, Harper E, Loat CS. The genetic basis for sex differences in human behaviour: role of the sex chromosomes. Ann Hum Genet. 2004;68:269-84.

Creswell CS, Skuse DH. Autism in association with Turner syndrome: genetic implications for male vulnerability to pervasive developmental disorders. Neurocase. 1999;5:511-8.

Cutter WJ, Daly EM, Robertson DMW, Chitnis XA, van Amelsvoort TAMJ, Simmons A, et al. Influence of $\mathrm{X}$ chromosome and hormones on human brain development: a magnetic resonance imaging and proton magnetic resonance spectroscopy study of Turner syndrome. Biol Psychiatry. 2006;59(3):273-83.

Daoud H, Bonnet-Brilhault F, Vedrine S, Demattei MV, Vourc'h P, Bayou N, et al. Autism and Nonsyndromic Mental retardation associated with a de novo mutation in the NLGN4X gene promoter causing an increased expression level. Biol Psychiatry. 2009;66(10):906-10.

Davenport ML. Evidence for early initiation of growth hormone and transdermal estradiol therapies in girls with Turner syndrome. Growth Horm IGF Res. 2006;16:S91-7.

Davenport ML, Quigley CA, Zagar AJ, Grp TTS. Linear growth deteriorates, while head circumference improves in infants and toddlers with Turner syndrome. Pediatr Res. 2002;51(4):115a-a.

Davenport ML, Crowe BJ, Travers SH, Rubin K, Ross JL, Fechner $\mathrm{PY}$, et al. Growth hormone treatment of early growth failure in toddlers with Turner syndrome: a randomized, controlled, multicenter trial. J Clin Endocrinol Metab. 2007;92(9):3406-16.

Davenport ML, Roush J, Liu C, Zagar AJ, Eugster E, Travers S, et al. Growth hormone treatment does not affect incidences of middle ear disease or hearing loss in infants and toddlers with Turner syndrome. Horm Res Paediatr. 2010;74:23-32.

Davies W, Wilkinson LS. It is not all hormones: alternative explanations for sexual differentiation of the human brain. Brain Res. 2006;1126:36-45.

Davies W, Isles A, Smith R, Karunadasa D, Burrmann D, Humby T, et al. $X l r 3 b$ is a new imprinted candidate for X-linked parent-oforigin effects on cognitive function in mice. Nat Genet. 2005;37 (6):625-9.

Davies W, Humby T, Isles AR, Burgoyne PS, Wilkinson LS. Xmonosomy effects on visuospatial attention in mice: a candidate gene and implications for Turner syndrome and attention deficit hyperactivity disorder. Biol Psychiatry. 2007;61(12):1351-60. 
De Vries G, Simerly RB. Anatomy, development, and function of sexually dimorphic neural circuits in the mammalian brain. In: Pfaff D, Arnold A, Etgen A, Fahrbach S, Rubin R, editors. Hormones, Brain and Behavior. New York: Academic; 2002. p. 137-91.

De Vries GJ, Rissman EF, Simerly RB, Yang L, Scordalakes EM, Auger CJ, et al. A model system for study of sex chromosome effects of sexually dimorphic neural and behavioral traits. J Neurosci. 2002;22(20):9005-14.

Denman S. Neuropsychology memory scale. Charleston: S Denman; 1984.

Dobkin C, Radu G, Ding XH, Brown WT, Nolin SL. Fragile X prenatal analyses show full mutation females at high risk for mosaic Turner syndrome: fragile $\mathrm{X}$ leads to chromosome loss. Am J Med Genet A. 2009;149A(10):2152-7.

Doherty MJ, Glass IA, Bennett CL, Cotter PD, Watson NF, Mitchell $\mathrm{AL}$, et al. An Xp; Yq translocation causing a novel contiguous gene syndrome in brothers with generalized epilepsy, ichthyosis, and attention deficits. Epilepsia. 2003;44(12):1529-35.

Elia J, Gai X, Xie H, Perin J, Geiger E, Glessner J, et al. Rare structural variants found in attention-deficit hyperactivity disorder are preferentially associated with neurodevelopmental genes. Mol Psychiatry. 2010;15(6):637-46.

Elliott TK, Watkins JM, Messa C, Lippe B, Chugani H. Positron emission tomography and neuropsychological correlations in children with Turner's syndrome. Dev Neuropsychol. 1996;12 (3):365-86

Fechner PY, Davenport ML, Qualy RL, Ross JL, Gunther DF, Eugster $\mathrm{EA}$, et al. Differences in follicle-stimulating hormone secretion between 45, X monosomy Turner syndrome and 45, X/46, XX mosaicism are evident at an early age. J Clin Endocrinol Metab. 2006;91(12):4896-902.

Feng JN, Schroer R, Yan J, Song WJ, Yang CM, Bockholt A, et al. High frequency of neurexin 1 beta signal peptide structural variants in patients with autism. Neurosci Lett. 2006;409(1):10-3.

Fombonne E. The changing epidemiology of autism. J Appl Res Intellect Disabil. 2005;18(4):281-94.

Friedman JI, Vrijenhoek T, Markx S, Janssen IM, Van der Vliet WA, Faas BHW, et al. CNTNAP2 gene dosage variation is associated with schizophrenia and epilepsy. Mol Psychiatry. 2008;13 (3):261-6.

Good CD, Lawrence K, Thomas NS, Price CJ, Ashburner J, Friston $\mathrm{KJ}$, et al. Dosage-sensitive X-linked locus influences the development of amygdala and orbitofrontal cortex, and fear recognition in humans. Brain. 2003;126:2431-46.

Grumbach MM, Auchus RJ. Commentary-estrogen consequences and implications of human mutations in synthesis and action. J Clin Endocrinol Metab. 1999;84(12):4677-94.

Gullotta F, Rehder H. Chromosomal anomalies and central nervoussystem. Beitrage Zur Pathologie. 1974;152(1):74-80.

Gunnell D, Miller LL, Rogers I, Holly JMP, Team AS. Association of insulin-like growth factor I and insulin-like growth factor-binding protein-3 with intelligence quotient among 8- to 9-year-old children in the Avon longitudinal study of parents and children. Pediatrics. 2005;116(5):E681-6.

Haaland KY, Delaney HD. Motor deficits after left or right-hemisphere damage due to stroke or tumor. Neuropsychologia. 1981;19 (1):17-27.

Haberecht MF, Menon V, Warsofsky IS, White CD, Dyer-Friedman J, Glover GH, et al. Functional neuroanatomy of visuo-spatial working memory in Turner syndrome. Hum Brain Mapp. 2001;14(2):96-107.

Hart SJ, Davenport ML, Hooper SR, Belger A. Visuospatial executive function in Turner syndrome: functional MRI and neurocognitive findings. Brain. 2006;129:1125-36.

Hazlett HC, Poe M, Gerig G, Smith RG, Provenzale J, Ross A, et al. Magnetic resonance imaging and head circumference study of brain size in autism - birth through age 2 years. Arch Gen Psychiatry. 2005;62(12):1366-76.

Henn W, Zhang KD. Mosaicism in Turner's syndrome. Nature. 1997;390:569.

Hines M. Sexual differentiation of human brain and behavior. In: Pfaff D, Arnold A, Etgen A, Fahrbach S, Rubin R, editors. Hormones, Brain and Behavior. New York: Academic; 2002. p. 425-62.

Holzapfel M, Barnea-Goraly N, Eckert MA, Kesler SR, Reiss AL. Selective alterations of white matter associated with visuospatial and sensorimotor dysfunction in Turner syndrome. J Neurosci. 2006;26(26):7007-13.

Hooper SR, Davenport ML, Ross JL. Neurocognitive and psychosocial dysfunction in preschool children with Turner syndrome. In: 113th Annual Convention of the American Psychological Association. Washington; 2005.

Hultcrantz M. Ear and hearing problems in Turner's syndrome. Acta Otolaryngol. 2003;123(2):253-7.

Jacobs PA, Melville M, Ratcliff S, Keay AJ, Syme J. Cytogenetic survey of 11,680 newborn-infants. Ann Hum Genet. 1974;37(4):359-76.

Jamain S, Quach H, Betancur C, Rastam M, Colineaux C, Gillberg IC, et al. Mutations of the $\mathrm{X}$-linked genes encoding neuroligins NLGN3 and NLGN4 are associated with autism. Nat Genet. 2003;34(1):27-9.

Johnston CM, Lovell FL, Leongamornlert DA, Stranger BE, Dermitzakis ET, Ross MT. Large-scale population study of human cell lines indicates that dosage compensation is virtually complete. PloS Genet. 2008;4(1): e9. doi:10.1371/journal.pgen.0040009

Kagan J. Reflection-impulsivity - generality and dynamics of conceptual tempo. J Abnorm Psychol. 1966;71(1):17-27.

Kaufman A. K-ABC Assessment Battery for Children. Circle Pines: American Guidance Service; 1983.

Kawanishi C, Kono M, Onishi H, Ishii N, Ishii K. A case of Turner syndrome with schizophrenia: genetic relationship between Turner syndrome and psychosis. Psychiatry Clin Neurosci. 1997;51(2):83-5.

Kent L, Emerton J, Bhadravathi V, Weisblatt E, Pasco G, Willatt LR, et al. X-linked ichthyosis (steroid sulfatase deficiency) is associated with increased risk of attention deficit hyperactivity disorder, autism and social communication deficits. J Med Genet. 2008;45 (8):519-24.

Kesler SR, Blasey CM, Brown WE, Yankowitz J, Zeng SM, Bender $\mathrm{BG}$, et al. Effects of X-monosomy and X-linked imprinting on superior temporal gyrus morphology in Turner syndrome. Biol Psychiatry. 2003;54:636-46.

Kesler SR, Garrett A, Bender B, Yankowitz J, Zeng SM, Reiss AL. Amygdala and hippocampal volumes in Turner syndrome: a high-resolution MRI study of X-monosomy. Neuropsychologia. 2004;42(14):1971-8.

Kesler SR, Menon V, Reiss AL. Neurofunctional differences associated with arithmetic processing in Turner syndrome. Cereb Cortex. 2006;16(6):849-56.

Kim HG, Kishikawa S, Higgins AW, Seong IS, Donovan DJ, Shen Y, et al. Disruption of neurexin 1 associated with autism spectrum disorder. Am J Hum Genet. 2008;82(1):199-207.

Kirov G, Gumus D, Chen W, Norton N, Georgieva L, Sari M, et al. Comparative genome hybridization suggests a role for $N R X N 1$ and APBA2 in schizophrenia. Hum Mol Genet. 2008;17(3):458-65.

Kirov G, Grozeva D, Norton N, Ivanov D, Mantripragada KK, Holmans P, et al. Support for the involvement of large copy number variants in the pathogenesis of schizophrenia. Hum Mol Genet. 2009;18(8):1497-503.

Klein KO, Baron J, Colli MJ, Mcdonnell DP, Cutler GB. Estrogenlevels in childhood determined by an ultrasensitive recombinant cell bioassay. J Clin Investig. 1994;94(6):2475-80.

Kubota T, Wakui K, Nakamura T, Ohashi H, Watanabe Y, Yoshino M, et al. The proportion of cells with functional $\mathrm{X}$ disomy is 
associated with the severity of mental retardation in mosaic ring X Turner syndrome females. Cytogenet Genome Res. 2002;99(14):276-84.

Kulkarni J. Oestrogen - a new treatment approach for schizophrenia? Med J Australia. 2009;190(4):S37-8.

Lam C, Yeung W, Ko C, Poon P, Tong S, Chan K, et al. Spectrum of mutations in the MECP2 gene in patients with infantile autism and Rett syndrome. J Med Genet. 2000;37:E41.

Laumonnier F, Bonnet-Brihault F, Gomot M, Blanc R, David A, Moizard $\mathrm{M}$, et al. X-linked mental retardation and autism are associated with a mutation in the NLGN4 gene, a member of the neuroligin family. Am J Hum Genet. 2004;74:552-7.

Lawson-Yuen A, Saldivar JS, Sommer S, Picker J. Familial deletion within NLGN4 associated with autism and Tourette syndrome. Eur J Hum Genet. 2008;16(5):614-8.

Leone P, Comoletti D, Ferracci G, Conrod S, Garcia SU, Taylor P, et al. Structural insights into the exquisite selectivity of neurexin/ neuroligin synaptic interactions. EMBO J. 2010;29(14):2461-71.

Liederman J, Kantrowitz L, Flannery K. Male vulnerability to reading disability is not likely to be a myth: a call for new data. J Learn Disabil. 2005;38(2):109-29.

Livadas S, Xekouki P, Fouka F, Kanaka-Gantenbein C, Kaloumenou I, Mavrou A, et al. Prevalence of thyroid dysfunction in Turner's syndrome: a long-term follow-up study and brief literature review. Thyroid. 2005;15(9):1061-6.

Lord C, Schopler E, Revicki D. Sex-differences in autism. J Autism Dev Disord. 1982;12(4):317-30.

Majewska MD. Neurosteroids - endogenous bimodal modulators of the GABA-A receptor - mechanism of action and physiological significance. Prog Neurobiol. 1992;38(4):379-95.

McCarney D. Test of Variables of Attention (TOVA). St. Paul: Attention Technology; 1990

Mccarthy MM. Molecular aspects of sexual-differentiation of the rodent brain. Psychoneuroendocrinology. 1994;19(5-7):415-27.

McCarthy MM, Amateau SK, Mong JA. Steroid modulation of astrocytes in the neonatal brain: implications for adult reproductive function. Biol Reprod. 2002;67(3):691-8.

McQuillen PS, Miller SP. Congenital heart disease and brain development. Year in Neurology 2. 2010;1184:68-86.

Menke LA, Sas TCJ, Visser M, Kreukels BPC, Stijnen T, Zandwijken GRJ, et al. The effect of the weak androgen oxandrolone on psychological and behavioral characteristics in growth hormone-treated girls with Turner syndrome. Horm Behav. 2010;57(3):297-305.

Moffitt TE. Juvenile-delinquency and attention deficit disorder-boys developmental trajectories from age 3 to age 15. Child Dev. 1990;61(3):893-910.

Moffitt TE, Caspi A. Childhood predictors differentiate life-course persistent and adolescence-limited antisocial pathways among males and females. Dev Psychopathol. 2001;13(2):355-75.

Molko N, Cachia A, Riviere D, Mangin JF, Bruandet M, Le Bihan D, et al. Functional and structural alterations of the intraparietal sulcus in a developmental dyscalculia of genetic origin. Neuron. 2003;40(4):847-58.

Molko N, Cachia A, Riviere D, Mangin JF, Bruandet M, LeBihan D, et al. Brain anatomy in Turner syndrome: evidence for impaired social and spatial-numerical networks. Cereb Cortex. 2004;14 (8):840-50

Molland EA, Purcell M. Biliary atresia and Dandy-Walker anomaly in a neonate with 45,X Turners syndrome. J Pathol. 1975;115 (4):227.

Money J, Alexander D, Walker H. A standardized road map of directional sense. Baltimore: Johns Hopkins Press; 1965.

Mors O, Mortensen PB, Ewald H. No evidence of increased risk for schizophrenia or bipolar affective disorder in persons with aneuploidies of the sex chromosomes. Psychol Med. 2001;31 (3):425-30
Mortensen KH, Cleemann L, Hjerrild BE, Nexo E, Locht H, Jeppesen EM, et al. Increased prevalence of autoimmunity in Turner syndrome-influence of age. Clin Exp Immunol. 2009;156 (2):205-10.

Mullen EM. Mullens Scales of Early Development. Circle Pines: American Guidance Service Inc.; 1995.

Need AC, Ge DL, Weale ME, Maia J, Feng S, Heinzen EL, et al. A genome-wide investigation of SNPs and CNVs in schizophrenia. Plos Genetics. 2009;5(2):e1000373.

Nelson HD, Nygren P, Walker M, Panoscha R. Screening for speech and language delay in preschool children: systematic evidence review for the US preventive services task force. Pediatrics. 2006;117(2):E298-319.

Nielsen J, Wohlert M. Chromosome-abnormalities found among 34910 newborn children - results from a 13-year incidence study in Arhus, Denmark. Hum Genet. 1991;87(1):81-3.

Noor A, Whibley A, Marshall CR, Gianakopoulos PJ, Piton A, Carson AR, et al. Disruption at the PTCHD1 locus on Xp22.11 in autism spectrum disorder and intellectual disability. Sci Transl Med. 2010;2(49):49-68.

Nyberg F. Growth hormone in the brain: characteristics of specific brain targets for the hormone and their functional significance. Front Neuroendocrinol. 2000;21(4):330-48.

Pasquino AM, Passeri F, Pucarelli I, Segni M, Municchi G. Spontaneous pubertal development in Turner's syndrome. J Clin Endocrinol Metab. 1997;82(6):1810-3.

Pinto D et al. Functional impact of global rare copy number variation in autism spectrum conditions. Nature. 2010;466(7304):368-72.

Prior TI, Chue PS, Tibbo P. Investigation of Turner syndrome in schizophrenia. Am J Med Genet. 2000;96(3):373-8.

Qi HB, Xing LX, Zhan KJ, Gao XC, Zheng ZJ, Huang SP, et al. Positive association of neuroligin-4 gene with nonspecific mental retardation in the Qinba Mountains Region of China. Psychiatr Genet. 2009;19(1):1-5.

Rae C, Joy P, Harasty J, Kemp A, Kuan S, Christodoulou J, et al. Enlarged temporal lobes in Turner syndrome: an X-chromosome effect? Cereb Cortex. 2004;14(2):156-64.

Rahhal SN, Fuqua JS, Lee PA. The impact of assay sensitivity in the assessment of diseases and disorders in children. Steroids. 2008;73(13):1322-7.

Ranke MB, Grauer ML. Adult height in Turner syndrome-results of a multinational survey 1993. Horm Res. 1994;42(3):90-4.

Rao E, Weiss B, Fukami M, Rump A, Niesler B, Mertz A, et al. Pseudoautosomal deletions encompassing a novel homeobox gene cause growth failure in idiopathic short stature and Turner syndrome. Nat Genet. 1997;16(1):54-63.

Rasika S, Alvarez-Buylla A, Nottebohm F. BDNF mediates the effects of testosterone on the survival of new neurons in an adult brain. Neuron. 1999;22(1):53-62.

Reisert I, Pilgrim C. Sexual-differentiation of monoaminergic neurons — genetic or epigenetic. Trends Neurosci. 1991;14(10):468-73.

Reskenielsen E, Christensen AL, Nielsen J. A neuropathological and neuropsychological study of Turners syndrome. Cortex. 1982;18 (2):181-90.

Romans SM, Stefanatos G, Roeltgen DP, Kushner H, Ross JL. Transition to young adulthood in Ullrich-Turner syndrome: neurodevelopmental changes. Am J Med Genet. 1998;79 (2):140-7.

Roser P, Kawohl W. Turner syndrome and schizophrenia: a further hint for a role of the $\mathrm{X}$-chromosome in the pathogenesis of schizophrenic disorders. World J Biol Psychiatry. 2010;11 (2):239-42

Ross JL, Roeltgen D, Feuillan P, Kushner H, Cutler GB. Effects of estrogen on nonverbal processing speed and motor function in girls with Turner's syndrome. J Clin Endocrinol Metab. 1998;83 (9):3198-204. 
Ross JL, Roeltgen D, Feuillan P, Kushner H, Cutler GB. Use of estrogen in young girls with Turner syndrome-effects on memory. Neurology. 2000a;54(1):164-70.

Ross JL, Roeltgen D, Kushner H, Wei FL, Zinn AR. The Turner syndrome-associated neurocognitive phenotype maps to distal Xp. Am J Hum Genet. 2000b;67(3):672-81.

Ross JL, Stefenatos GA, Kushner H, Zinn A, Bondy C, Roeltgen D. Persistent cognitive deficits in adult women with Turner syndrome. Neurology. 2002;58(2):218-25.

Ross JL, Roeltgen D, Stefanatos GA, Feuillan P, Kushner H, Bondy C, et al. Androgen-responsive aspects of cognition in girls with Turner syndrome. J Clin Endocrinol Metab. 2003;88(1):292-6.

Ross MT, Grafham DV, Coffey AJ, Scherer S, McLay K, Muzny D, et al. The DNA sequence of the human $\mathrm{X}$ chromosome. Nature. 2005;434(7031):325-37.

Ross J, Roeltgen D, Zinn A. Cognition and the sex chromosomes: studies in Turner syndrome. Horm Res. 2006;65(1):47-56.

Rossi E, Verri AP, Patricelli MG, Destefani V, Ricca I, Vetro A, et al. A $12 \mathrm{Mb}$ deletion at $7 \mathrm{q} 33-\mathrm{q} 35$ associated with autism spectrum disorders and primary amenorrhea. Eur J Med Genet. 2008;51 (6):631-8.

Rovet J. Turner syndrome: a review of genetic and hormonal influences on neuropsychological functioning. Child Neuropsychol. 2004;10(4):262-79.

Rujescu D, Ingason A, Cichon S, Pietilainen OPH, Barnes MR, Toulopoulou T, et al. Disruption of the neurexin 1 gene is associated with schizophrenia. Hum Mol Genet. 2009;18(5):988-96.

Russell HF, Wallis D, Mazzocco MMM, Moshang T, Zackai E, Zinn $\mathrm{AR}$, et al. Increased prevalence of ADHD in Turner syndrome with no evidence of imprinting effects. J Pediatr Psychol. 2006;31(9):945-55.

Rutter M, Caspi A, Moffitt TE. Using sex differences in psychopathology to study causal mechanisms: unifying issues and research strategies. J Child Psychol Psychiatry Allied Disciplines. 2003;44 (8):1092-115.

Saenger P, Wikland KA, Conway GS, Davenport M, Gravholt CH, Hintz $\mathrm{R}$, et al. Recommendations for the diagnosis and management of Turner syndrome. J Clin Endocrinol Metab. 2001;86(7):3061-9.

Sagi L, Zuckerman-Levin N, Gawlik A, Ghizzoni L, Buyukgebiz A, Rakover Y, et al. Clinical significance of the parental origin of the $\mathrm{X}$ chromosome in Turner syndrome. J Clin Endocrinol Metab. 2007;92(3):846-52.

Salameh EK, Nettelbladt U, Gullberg B. Risk factors for language impairment in Swedish bilingual and monolingual children relative to severity. Acta Paediatr. 2002;91(12):1379-84.

Sandberg DE, Voss LD. The psychosocial consequences of short stature: a review of the evidence. Best Pract Res Clin Endocrinol Metab. 2002;16(3):449-63.

Savendahl L, Davenport ML. Delayed diagnoses of Turner's syndrome: proposed guidelines for change. J Pediatr. 2000;137 (4):455-9.

Schmitt A, Parlapani E, Bauer M, Heinsen H, Falkai P. Is brain banking of psychiatric cases valuable for neurobiological research? Clinics. 2008;63(2):255-66.

Shinawi M, Patel A, Panichkul P, Zascavage R, Peters SU, Scaglia F. The Xp contiguous deletion syndrome and autism. Am J Med Genet A. 2009;149A(6):1138-48.

Simerly RB. Wired for reproduction: organization and development of sexually dimorphic circuits in the mammalian forebrain. Annu Rev Neurosci. 2002;25:507-36.

Skuse DH. Imprinting, the X-chromosome, and the male brain: explaining sex differences in the liability to autism. Pediatr Res. 2000;47:9-16.

Skuse DH, James RS, Bishop DVM, Coppins B, Dalton P, AamondtLeeper G, et al. Evidence from Turner's syndrome of an imprinted X-linked locus affecting cognitive function. Nature. 1997;387(12):705-8.

Skuse DH, Morris JS, Dolan RJ. Functional dissociation of amygdalamodulated arousal and cognitive appraisal, in Turner syndrome. Brain. 2005;128:2084-96.

Sparrow S, Balla DA. Vineland Social-Emotional Early Childhood Scales. Circle Pines: American Guidance Service; 1998.

Stone JL, O’Donovan MC, Gurling H, Kirov GK, Blackwood DHR, Corvin A, et al. Rare chromosomal deletions and duplications increase risk of schizophrenia. Nature. 2008;455 (7210):237-41.

Sumner BEH, Fink G. Testosterone as well as estrogen increases serotonin(2A) receptor mRNA and binding site densities in the male rat brain. Mol Brain Res. 1998;59(2):205-14.

Sybert VP. Cardiovascular malformations and complications in Turner syndrome. Pediatrics. 1998;101:1-7.

Sybert VP, McCauley E. Turner's syndrome. N Engl J Med. 2004;351 (12): $1227-38$

Szatmari P, Offord DR, Boyle MH. Ontario Child Health Studyprevalence of attention deficit disorder with hyperactivity. J Child Psychol Psychtr Allied Disc. 1989;30(2):219-30.

Szatmari P, Paterson AD, Zwaigenbaum L, Roberts W, Brian J, Liu XQ, et al. Mapping autism risk loci using genetic linkage and chromosomal rearrangements. Nat Genet. 2007;39(3):319-28.

Talebizadeh Z, Lam DY, Theodoro MF, Bittel DC, Lushington $\mathrm{GH}$, Butler MG. Novel splice isoforms for $N L G N 3$ and NLGN4 with possible implications in autism. J Med Genet. 2006;43(5):e21.

Thornton J, Zehr JL, Loose MD. Effects of prenatal androgens on rhesus monkeys: a model system to explore the organizational hypothesis in primates. Horm Behav. 2009;55(5): 633-44.

Tucker DM, Roeltgen MG, Roeltgen DP, Kline R, Kline J. Dyslexia and impaired phonological memory. J Clin Exp Neuropsychol. 1974;11(26):Abstract

Urich H. Cerebellar malformations: Some pathogenetic considerations. Clin Exp Neurol. 1979;16:119031.

Waber DP, Holmes JM. Assessing children's copy productions of the Rey-Osterrieth complex figure. J Clin Exp Neuropsychol. 1985;7 (3):264-80.

Walsh T, McClellan JM, McCarthy SE, Addington AM, Pierce SB, Cooper GM, et al. Rare structural variants disrupt multiple genes in neurodevelopmental pathways in schizophrenia. Science. 2008;320(5875):539-43.

Wang HS, Kuo MF. Tourette's syndrome in Taiwan: an epidemiological study of tic disorders in an elementary school at Taipei County. Brain Dev. 2003;25:S29-31.

Wang ZX, Bullock NA, Devries GJ. Sexual-differentiation of vasopressin projections of the bed nucleus of the stria terminals and medial amygdaloid nucleus in rats. Endocrinology. 1993;132 (6):2299-306.

Warrington E. Recognition Memory Test. Windsor: Nfer-Nelson Publishing Company; 1984.

Warrington E, James M. The visual object and perception battery. Suffolk: Thames Valley Test Company; 1991.

Wechsler D. Wechsler Intelligence Scale for Children-revised. San Antonio: Psychological Corporation; 1974.

Wechsler D. Wechsler Memory Scale — revised manual. San Antonio: The Psychological Corporation; 1987.

Weiss LA, Purcell S, Waggoner S, Lawrence K, Spektor D, Daly MJ, et al. Identification of $E F H C 2$ as a quantitative trait locus for fear recognition in Turner syndrome. Hum Mol Genet. 2007;16 (1):107-13.

Williams GR. Neurodevelopmental and neurophysiological actions of thyroid hormone. J Neuroendocrinol. 2008;20(6):784-94. 
Yan J, Oliveira G, Coutinho A, Yang C, Feng J, Katz C, et al. Analysis of the neuroligin 3 and 4 genes in autism and other neuropsychiatric patients. Mol Psychiatry. 2005;10(4):329-32.

Yang LY, Verhovshek T, Sengelaub DR. Brain-derived neurotrophic factor and androgen interact in the maintenance of dendritic morphology in a sexually dimorphic rat spinal nucleus. Endocrinology. 2004;145(1):161-8.

Zhang JM, Konkle ATM, Zup SL, McCarthy MM. Impact of sex and hormones on new cells in the developing rat hippocampus: a novel source of sex dimorphism? Eur J Neurosci. 2008;27(4):791-800.

Zinn AR, Roeltgen D, Stefanatos G, Ramos P, Elder FF, Kushner H, et al. A Turner syndrome neurocognitive phenotype maps to Xp22.3. Behav Brain Funct. 2007;3:24.
Zinn AR, Kushner H, Ross JL. EFHC2 SNP rs7055196 is not associated with fear recognition in 45, $\mathrm{X}$ Turner syndrome. Am J Med Genet B Neuropsychiatr Genet. 2008;147B (4):507-9.

Zuckerman-Levin N, Frolova-Bishara T, Militianu D, Levin M, Aharon-Peretz J, Hochberg Z. Androgen replacement therapy in Turner syndrome: a pilot study. J Clin Endocrinol Metab. 2009;94(12):4820-7.

Zweier C, de Jong E, Zweier M, Orrico A, Ousager L, Collins A, et al. CNTNAP2 and NRXN1 are mutated in autosomal-recessive PittHopkins-like mental retardation and determine the level of a common synaptic protein in Drosophila. Am J Hum Genet. 2009;85(5):655-66. 